\title{
Global processing deficit in Alzheimer's disease
}

\section{Déficit del procesamiento global en la enfermedad de Alzheimer}

\author{
María J. Blanca, Teresa Rodrigo and Rebecca Bendayan \\ University of Malaga
}

Disponible online 30 de agosto de 2010

\begin{abstract}
Several studies of Alzheimer's disease (AD) reveal an impaired capacity to integrate visual elements into global pictures, leading to a deficit in global processing of visual information. The aim of this paper was to explore global and local processing in people with AD at non-advanced stage. The Global and Local Attention Test (AGL; from the original Spanish: AGL-Atención global y local) was administered to a group of 100 participants with a mean age of 75.36 years. Fifty of them were AD patients at a mild or moderate stage, while the remainder comprised healthy elders. The AGL provides two scores that indicate speed and accuracy in analyzing global and local figures. Participants had to indicate the figures where the target appeared at either global or local levels in a divided attention task. The results showed lower accuracy in the AD group compared with controls. Also in the AD group, and in line with previous findings, accuracy in detecting the target was much lower at the global level than at the local level, thereby confirming the expected deficit in global processing associated with $\mathrm{AD}$. This deficit did not vary according to sex or age.
\end{abstract}

Keywords: Alzheimer, global processing, local processing.

Diversos estudios revelan que la enfermedad de Alzheimer (AD) disminuye la habilidad para integrar los elementos visuales en imágenes globales, provocando un déficit del procesamiento global de la información visual en comparación con el local. El objetivo del presente trabajo es analizar el procesamiento global y local en personas con estados no avanzados de AD. Para ello, se ha administrado el test AGL-Atención global y local a un grupo de 100 participantes con una edad media de 75,36 años, de los cuales 50 eran pacientes con $\mathrm{AD}$ en fase de demencia leve o moderada y 50 eran participantes que no presentaban ninguna patología. El test arroja dos puntuaciones indicativas, respectivamente, de la rapidez y exactitud en analizar los rasgos globales y los locales. Los participantes realizan una tarea de atención dividida, señalando las figuras coincidentes con una figura objetivo cuando ésta aparece en el nivel global o en el local. Los resultados, de forma consistente con los estudios previos, muestran que la ejecución global fue mucho menor que la local en el grupo AD que en el grupo control, obteniéndose una clara evidencia de un déficit en el procesamiento global asociado a la AD. Este déficit no varía en función del sexo o de la edad.

Palabras claves: Alzheimer, procesamiento global, procesamiento local.

Correspondence: María J. Blanca, Dpto. de Psicobiología y Metodología de las Ciencias del Comportamiento, Facultad de Psicología, Campus Universitario de Teatinos, s/n, Málaga, 29071, Tel. (+34) 9521310 88, blamen@uma.es 
Alzheimer's disease (AD) is a progressive neurodegenerative disorder that is characterized by progressive memory loss and additional cognitive impairments of gradual onset and which show a continual decline. Several studies reveal that visual perception and attention are impaired at early stages of AD (Adlington, Laws, \& Gale, 2009; Baddeley, Baddeley, Bucks, \& Wilcock, 2001; Valenti, 2010), and hence these deficits could help to detect AD prior to the loss of cognitive and memory functions (Valenti, 2010). Deficits in visual processing in $\mathrm{AD}$ are related to neuropathological changes in specific areas of the brain (Backus, Fleet, Parker, \& Heeger, 2001; CroninGolomb, Gilmore, Neargarder, Morrison, \& Laudatte, 2007; Nishida et al., 2001; Thiyagesh et al., 2009; Zakzanis, Graham, \& Campbell, 2003). Zakzanis et al. (2003) conducted a review of structural and functional imaging which included hippocampal deterioration as neuroimaging profile for early stages of $\mathrm{AD}$, and a pathology within the medial temporal lobes and the anterior cingulate gyrus for longer duration patients with AD. Thiyagesh et al. (2009) compared AD patients with healthy elderly participants in response to a visuospatial task using functional magnetic resonance imaging (fMRI) and they found that patients with $\mathrm{AD}$ showed hypoactivation in, among other regions, the superior parietal lobe, parieto-occipital cortex and premotor cortices, as well as increased activation in the inferior parietal lobule.

Most aspects of visual cognition are impaired in AD, including face processing (Tippett, Blackwood, \& Farah, 2003; Farah, Levinson, \& Klein, 1995), object recognition and naming (Adlington et al., 2009; Laws, Adlington, Gale, Moreno-Martínez, \& Sartori, 2007; Viggiano et al., 2007), visuomotor integration (Ghilardi et al., 1999; Tippett \& Sergio, 2006), spatial contrast sensitivity (Cronin-Golomb et al., 2007; Rizzo, Anderson, Dawson, \& Nawrot, 2000; Viggiano et al., 2007) and visual-perceptual organization ability (Kurylo, Corkin, Rizzo, \& Growdon, 1996; Paxton et al., 2007). Likewise, the ability to integrate visual elements into global shapes decreases in patients with $\mathrm{AD}$, causing deficits in global processing compared to local processing, even at very early stages of the disease (Fernández-Duque \& Black, 2008; Matsumoto, Ohigashi, Fujimori, \& Mori, 2000; Slavin, Mattingley, Bradshaw, \& Storey, 2002; Thomas \& Forde, 2006).

In general, the research carried out on global and local processing of visual information includes hierarchical stimuli, i.e., large figures, representing the global level, that are made up of small figures, representing the local level. Experiments include either selective or divided attention tasks. In selective attention tasks, participants are instructed to indicate whether or not the target appears at a specific level of the visual pattern, ignoring the other level. In divided attention tasks, participants have to detect the presence of the target in the stimulus wherever it appears, either at global or local levels. Using these experimental procedures, Slavin et al. (2002) showed that patients with $\mathrm{AD}$ process local features more quickly and more accurately than they do global ones, and also that they were slower to switch their attention between the levels of hierarchical stimuli in divided attention tasks.

Several researchers have proposed a hypothesis of an impaired 'spotlight' of attention to explain the global processing deficit. They suggest that patients with $\mathrm{AD}$ have a restricted attention spotlight, such that they have no problem in perceiving a local feature of the object but they fail to perceive enough features to integrate them and organize the object shape as a whole (Coslett, Stark, Rajarm, \& Saffran, 1995; Matsumoto et al., 2000; Stark, Grafman, \& Fertig, 1997).

The aim of this paper was to explore global and local processing in patients with $\mathrm{AD}$ at non-advanced stage compared to healthy elders. This was done by administering the Global and Local Attention Test (AGL; from the original Spanish: AGLAtención global y local; Blanca, Zalabardo, Rando, LópezMontiel, \& Luna, 2005). The AGL uses hierarchical stimuli and provides several scores that indicate speed and accuracy in analyzing global and local figures. If there is a global processing deficit related to $\mathrm{AD}$, people with $\mathrm{AD}$ would be expected to score lower when analyzing global figures rather than local ones, and this difference would be higher than that found among healthy elders.

\section{Method}

\section{Participants}

Participants were 100 individuals aged 60 years or over (42 men and 58 women). Fifty were AD patients with mild or moderate dementia (13 men and 37 women; $M=76.20$ years old, $S D=5.15)$ and 50 were healthy elders (29 men and 21 women; $M=74.52$ years old; $S D=6.60$ ). The sample distribution is shown in Table 1.

Table 1. Sample distribution as a function of group and age.

\begin{tabular}{ccc}
\hline Age & Control group & AD group \\
\hline $60-70$ & 9 & 11 \\
$71-80$ & 31 & 33 \\
$81-90$ & 10 & 6 \\
\hline
\end{tabular}

Participants with AD were recruited from a day clinic for people with Alzheimer's disease. They were all diagnosed by the dementia-assessment medical team of the clinic in accordance with Diagnostic and Statistical Manual IV-TR (American Psychiatric Association, 2000) criteria. All participants with AD scored between 14 and 26 on the Mini Mental State Examination (Folstein, Folstein, \& McHugh, 1975; Folstein, Folstein, McHugh, \& Fanjiang, 2001). Relatives or guardians signed an informed consent form. The control group was recruited in nursing homes for the elderly. Healthy elders who agreed to participate gave their own informed consent. Controls fulfilled the following criteria: a score of at least 27 on the Mini Mental; 
age 60 or older; not suffering from any medical or neurological condition that would likely affect their cognitive performance; and not reporting any memory deficits. All participants had normal or corrected-to-normal vision.

\section{Apparatus}

The Mini Mental State Examination (MMSE; Folstein et al., 1975, 2001) was administered to all the participants. The MMSE is used to screen for cognitive deficits, estimate their severity, and follow their course over time. It explores a number of areas such as orientation to time, orientation to place, registration, attention and calculation, recall, naming, repetition, comprehension, reading, writing, and drawing. A score of 27 points or more indicates a normal cognitive function. Lower scores can indicate mild deficit (21-26 points), moderate deficit (11-20 points) or severe deficit (0-10 points).

The Global and Local Attention Test (AGL; from the original Spanish: AGL-Atención global y local; Blanca et al., 2005) was administered to assess the ability to process global and local figures. This test is based on hierarchical stimuli, i.e., large figures, representing the global level, that are made up of small figures, representing the local level. The figures were large incomplete squares, that is, squares with the right $(\sqsubset)$, left $(\sqsupset)$, superior $(\sqcup)$ or inferior $(\sqcap)$ side missing (Figure 1). The combinations of these figures at both levels generate different types of stimuli that are presented in series of 30 on each page. Participants have to indicate those figures in which the target (the incomplete square with its left side missing, $\sqsupset$ ) appears at either the global or local level. This task is a divided attention task because switching attention between both levels is required. The AGL provides the following scores: Global score or number of correct responses when detecting the target at the global level; Local score or number of correct responses when detecting the target at the local level; Total score, defined as the sum of the Global and Local scores; and the Relative Efficiency score, defined as the Global score minus the Local one. This study only considered accuracy in detecting the target at either the global or local level.

Figure 1. Example of stimuli included in the AG.

\begin{tabular}{|c|c|c|c|}
\hline$\sqcap$ & $\sqsupset$ & $\sqcup \sqcup \sqcup \sqcup$ & $\sqcup \sqcup \sqcup \sqcup$ \\
\hline$\sqcap$ & $\sqsupset$ & $\sqcup$ & $\sqcup$ \\
\hline & $\sqsupset$ & $\sqcup$ & $\sqcup$ \\
\hline$\sqcap \sqcap \sqcap$ Г & $\sqsupset コ コ$ & $\sqcup \sqcup \sqcup \sqcup$ & $\sqcup$ \\
\hline
\end{tabular}

Target: $\sqsupset$

\section{Procedure}

The tests were administered individually, by a trained psychologist, in a silent room at the participant's usual place of residence and without any interruptions. The MMSE was administered first, followed by the AGL in the same session.
Results

Previous data analysis revealed that sex had neither a main effect nor an interaction effect with any of the other factors considered. Therefore, sex was eliminated from the analyses in order to increase the number of participants in the cells. A $2 \times 3 \times 2$ analysis of variance (ANOVA) with two grouping factors and one within factor was subsequently performed. The grouping factors were group (control and Alzheimer groups) and age (60-70, 71-80 and 81-90 years old). The within factor was target level (global and local levels). The accuracy or number of correct responses when detecting the target on the AGL was recorded. Descriptive statistics are shown in Table 2 and ANOVA results in Table 3.

Table 2. Mean accuracy on the AGL as a function of group, age and target level (standard deviations are shown in brackets).

\begin{tabular}{lccc}
\hline & Age & Global & Local \\
\hline Control & $60-70$ & $14.56(2.97)$ & $16.56(3.91)$ \\
& $71-80$ & $12.17(3.50)$ & $13.49(3.04)$ \\
& $81-90$ & $10.31(3.13)$ & $11.61(2.55)$ \\
\hline Alzheimer & $60-70$ & $1.55(0.94)$ & $7.46(1.64)$ \\
& $71-80$ & $1.64(1.06)$ & $7.61(1.64)$ \\
& $81-90$ & $1.51(0.84)$ & $6.51(1.04)$ \\
\hline
\end{tabular}

Table 3. Results from the group $\mathrm{x}$ age $\mathrm{x}$ target level ANOVA, showing degrees of freedom (d.f.), $F$ statistic, probability $(p)$ and effect size (partial eta square).

\begin{tabular}{lcccc}
\hline Effects & $d . f$. & $F$ & $p$ & partial $\eta^{2}$ \\
\hline Group & 1,94 & 296.95 & $<.001$ & .76 \\
Age & 2,94 & 6.49 & .002 & .12 \\
Target level & 1,94 & 124.56 & $<.001$ & .57 \\
Group x age & 2,94 & 4.89 & .01 & .09 \\
Group x target level & 1,94 & 40.47 & $<.001$ & .30 \\
Age x target level & 2,94 & 0.40 & .67 & .008 \\
Group x age x target level & 2,94 & 0.28 & .75 & .006 \\
\hline
\end{tabular}

The analysis of main effects revealed that the control group was more accurate $(M=13.11)$ than the $\mathrm{AD}$ group $(M=4.38)$. Furthermore, performance got worse as age increased. The number of correct responses decreased from 10.03 points in the age range of $60-70$ years to 8.72 points in the range $71-80$ years and to 7.47 points in the range $81-90$ years. Finally, accuracy in detecting the target at the local level $(M=10.54)$ was greater than at the global level $(M=6.95)$. However, these main effects were subordinate to the interaction effects.

The group $\mathrm{x}$ age interaction indicated that the accuracy of the control and AD groups differed as a function of age (Figure 2). In order to study this interaction effect, simple age effects were analyzed, keeping the group constant with Bonferroni adjustment (alpha per contrast: .025). The age effect was significant $\left[F(2,47)=6.62, p=.003\right.$, partial $\left.\eta^{2}=.22\right]$ in the control group, showing that accuracy decreases linearly as age increases $(p<.001)$, the quadratic component being not significant $(p=.19)$. By contrast, no differences were found in the AD group across the age ranges $[F(2,47)=0.95, p=.39]$. 
Figure 2. Target level as a function of group and age.

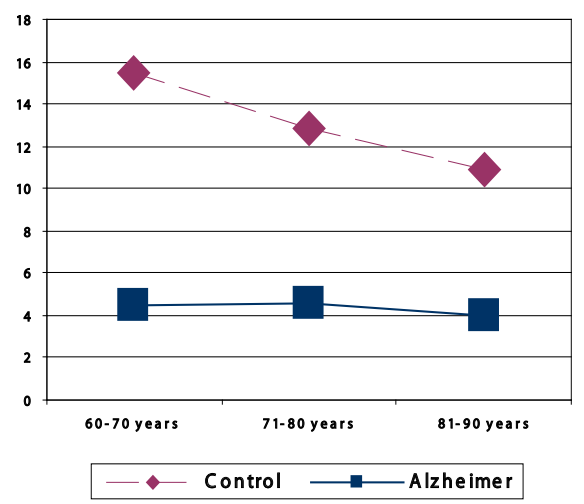

The group $\mathrm{x}$ target level interaction showed that accuracy at the global and local levels differed between the groups (Figure $3)$. In order to study this interaction effect, a t-test for related samples, with Bonferroni adjustment (alpha per contrast: .025) was performed for each group so as to compare global and local accuracy. In the control group, local level accuracy was 1.44 points higher than global accuracy $[t(49)=-3.19, p=.002$, $d=0.44]$, whereas in the AD group local accuracy was 5.84 points higher than that at the global level $[t(49)=-24.2, p<.001$, $d=3.43]$. Although the differences between global and local accuracy are significant for both groups, the difference in the control group is smaller than that in the AD group. The confidence intervals regarding this difference were $[-2.36,-0.51]$ in the control group and $[-6.35,-5.35]$ in the AD group. Furthermore, application of Cohen's criteria (1988) showed a medium effect size for the control group difference, whereas the much bigger difference in the $\mathrm{AD}$ group takes it beyond the cut-off for a large effect size.

Figure 3. Mean accuracy at the global and local levels as a function of group.

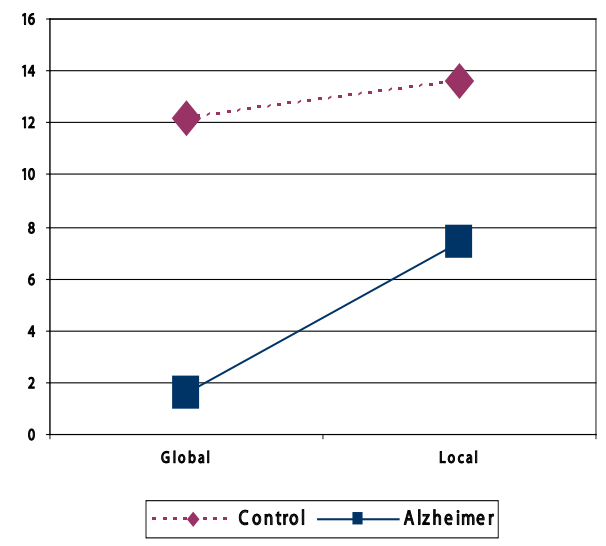

Discussion

The main aim of this paper was to analyze the deficit in global processing of visual information in patients with $\mathrm{AD}$ compared to healthy elders. To this end, the Global and Local Attention Test (AGL; from the original Spanish: AGL-Atención global y local; Blanca et al., 2005), which provides two scores that indicate speed and accuracy in global and local processing, was administered to a group of participants diagnosed with mild or moderate $\mathrm{AD}$ and to a control group of healthy elders.

The results showed that $\mathrm{AD}$ patients performed worse than healthy elders on both global and local processing. This poorer performance did not vary as a function of age. These findings are consistent with the impairments in visual perception and attention that have been reported in the early stages of $\mathrm{AD}$ (Adlington et al., 2009; Baddeley et al., 2001; Valenti, 2010). They also support the research which has shown that switching attention from global to local stimulus levels, as is required by the AGL, is more difficult for patients with AD (Slavin et al., 2002).

It should also be noted that the accuracy of the $\mathrm{AD}$ group in detecting the target at the global level was considerably less than what they achieved at the local level, thereby providing empirical evidence of the expected deficit in global processing. These results are consistent with previous findings which showed that $\mathrm{AD}$ reduces a person's ability to process global features (Fernández-Duque \& Black, 2008; Matsumoto et al., 2000; Slavin et al., 2002; Thomas \& Forde, 2006). Moreover, they support the hypothesis of an impaired spotlight of attention as an explanation for the difficulty in integrating and organizing visual elements into global shapes (Coslett et al., 1995; Matsumoto et al., 2000; Stark et al., 1997).

Greater accuracy in local as opposed to global processing was also observed in the group of healthy elders. However, from the clinical point of view, and given its magnitude of just 1.44 points, this difference is not indicative of a global processing deficit. Nevertheless, this finding does corroborate the results of Oken, Kishiyama, Kaye and Jones (1999) and those of Slavin et al. (2002), with both groups reporting that global processing declines with age. Finally, in the group of healthy elders both global and local performance got worse as age increased, which may be suggestive of the decline in cognitive function related to normal aging.

In conclusion, this study provides empirical evidence of the global processing deficit in $\mathrm{AD}$ patients, and supports the results of previous experimental studies. Cognitive and visual processing deficits in $\mathrm{AD}$ are known to affect everyday activities and make it more difficult for individuals to recognize living things (Viggiano et al., 2007). Some authors such as Thomas and Forde (2006) suggest that these difficulties in recognizing living things are associated with the global processing deficit.

\section{References}

Adlington, R.L., Laws, K.R., \& Gale, T.M. (2009). Visual processing in Alzheimer's disease: surface detail and colour fail to aid object identification. Neuropsychologia, 47, 2574-2583. 
American Psychiatric Association. (2000). Diagnostic and statistical manual of mental disorders (4th. Ed. text revision). Washington, DC: Author.

Baddeley, A.D., Baddeley, H.A., Bucks, R.S., \& Wilcock, G.K. (2001). Attentional control in Alzheimer's disease, Brain, 124, 1492-1508.

Backus, B.T., Fleet, D.J., Parker, A.J., \& Heeger, D.J. (2001). Human cortical activity correlates with stereoscopic depth perception. Journal of Neurophysiology, 86, 2054-2068.

Blanca, M. J., Zalabardo, C., Rando, B., López-Montiel, D., \& Luna, R. (2005). Test AGL, Atención global-local. Madrid: TEA Ediciones, S.A.

Cohen, J. (1988). Statistical power analysis for the behavioral sciences (2nd. Ed.). New Jersey: Lawrence Erlbaum Associates, Publishers.

Coslett, H.B., Stark, M.E, Rajarm, S., \& Saffran, E.M. (1995). Narrowing the spotlight: A visual attentional disorder in presumed Alzheimer's disease. Neurocase, 11, 305-318.

Cronin-Golomb, A., Gilmore, G.C., Neargarder, S., Morrison, S.R., \& Laudatte, T.M. (2007). Enhanced stimulus strength improves visual cognition in aging and Alzheimer's disease. Cortex, 43, 952-966.

Farah, M.J., Levinson, K.L., \& Klein, K.L. (1995). Face perception and within-category discrimination in prosopagnosia. Neuropsychologia, 33, 661-674.

Fernández-Duque, D. \& Black, S.E. (2008). Selective attention in early dementia of Alzheimer type. Brain and Cognition, $66,221-231$

Folstein, M.F., Folstein, S.E., \& McHugh, P.R. (1975). Minimental State: A practical method for grading cognitive state of the patients for the clinician. Journal of Psychiatric Research, 12, 189-98.

Folstein, M.F., Folstein S.E., McHugh P.R., \& Fanjiang, G. (2000). Mini-Mental State Examination: MMSE user's guide. Odessa, Fla.: Psychology Assessment Resources.

Ghilardi, M.F., Alberoni, M., Marelli, S., Rossi, M., Franceschi, M., Ghez, C., \& Fazio, F. (1999). Impaired movement control in Alzheimer's disease. Neuroscience Letters, 260 , 45-48.

Kurylo, D.D., Corkin, S., Rizzo, F.J., \& Growdon, J.H. (1996). Greater relative impairment of object recognition than of visuospatial abilities in Alzheimer's disease. Neuropsychology, 10, 74-81.

Laws, K.R., Adlington, R.L., Gale, T.M., Moreno-Martínez, J., \& Sartori, G. (2007). Meta-analysis of category naming in Alzheimer's disease. Neuropsychologia, 45, 2674-2682.

Matsumoto, E., Ohigashi, Y., Fijimori, M. \& Mori, E. (2000). The processing of global and local visual information in Alzheimer's disease. Behavioural Neurology, 12, 119-125.

Nishida, Y., Hayashi, O., Iwami, T., Kimura, M., Kani, K., Ito, R., Shiino, A., \& Suzuki, M. (2001). Stereopsis-processing regions in the human parieto-occipital cortex. Neuroreport, 12, 2259-2263.
Oken, B., Kishiyama, S.S., Kaye, J.A., \& Jones, D.E. (1999). Age-related differences in global-local processing: Stability of laterality differences but disproportionate impairment in global processing. Journal of Geriatric Psychiatry and Neurology, 12, 76-81.

Paxton, J.L., Peavy, G.M., Jenkins, C., Rice, V.A., Heindel, W.C., \& Salmon, D.P. (2007). Deterioration of visual-perceptual organization ability in Alzheimer's disease. Cortex, 43, 967-975.

Rizzo, M., Anderson, S.W., Dawson, J., \& Nawrot, M. (2000). Vision and cognition in Alzheimer's disease. Neuropsychologia, 38, 1157-1169.

Slavin, M. J., Mattingley, J. B., Bradshaw, J. L., \& Storey, E. (2002). Local-global processing in Alzheimer's disease: an examination of interference, inhibition and priming. Neuropsychologia, 40, 8, 1173-1186.

Stark, M.E., Grafman, J., \& Fertig, E. (1997). A restricted 'spotlight' of attention in visual object recognition. Neuropsychology, 35, 1233-1249.

Thiyagesh, S.N., Farrow, T.F., Parks, R.W., Accosta-Mesa, H., Young, C., Wilkinson, I.D., Hunter, M.D., \& Woodruff, P.W. (2009). The neural basis of visuospatial perception in Alzheimer's disease and healthy elderly comparison subjects: An fMRI study. Psychiatry Research: Neuroimaging, 172, 109-116.

Tippett, L.J., Blackwood, K., \& Farah, M.J. (2003). Visual object and face processing in mild-to-moderate Alzheimer's disease: From segmentation to imagination. Neuropsychologia, 41, 453-468.

Tippett, W.J. \& Sergio, L.E. (2006). Visuomotor integration is impaired in early stage Alzheimer's disease. Brain Research, 1102, 92-102.

Thomas, R. \& Forde, E. (2006). The role of local and global processing in the recognition of living and nonliving things. Neuropsychologia, 44, 982-986.

Valenti, D. (2010) Alzheimer's disease: Visual system review. Optometry, 81, 12-21.

Viggiano, M.P., Gori, G., Zaccara, G., Righi, S., Vanucci, M., \& Giovannelli, F. (2007). Category-specific visual identification of filtered objects in Alzheimer's disease. Archives of Gerontology and Geriatrics, 44, 125-139.

Zakzanis, K.K., Graham, S.J. \& Campbell, Z. (2003). A metaanalysis of structural and functional brain imaging in dementia of the Alzheimer's type: A neuroimaging profile. Neuropsychology Review, 13, 1, 1-18.

Received: April 19, 2010 Accepted: June 15, 2010 